Anuario Latinoamericano Ciencias Políticas

y Relaciones Internacionales

vol. 7, 2019

pp. 213-230

\section{Legitimidad y compromiso democrático. Impases contemporáneos en América Latina*}

\section{Legitimacy and Democratic Commitment. Contemporary Impasses in Latin America}

\author{
Maria do Socorro Sousa Braga ${ }^{\star *}$ \\ UNIVERSIDAD FEDERAL DE SAN CARLOS, \\ SÃO PAULO, BRASIL \\ $\triangle$ msbraga@ufscar.br \\ https://orcid.org/0000-0003-2141-9778 \\ Gabriel Avila Casalecchi ${ }^{* * *}$ \\ UNIVERSIDAD FEDERAL DE SAN CARLOS, \\ SÃO PAULO, BRASIL \\ $\triangle$ gacasalecchi@gmail.com \\ https://orcid.org/0000-0003-1637-0180
}

\title{
RESUMEN
}

Ante el contexto de la alternancia de grupos politicos más próximos a la extrema derecha en países de América Latina en las últimas elecciones nacionales, el objetivo de este artículo es evaluar algunas actitudes políticas de los ciudadanos y su relación con los cambios en el régimen político que permitan identificar cuál es el nivel la "reserva de legitimidad política" y de compromiso con la democracia en esta región. Para ello, el análisis es realizado mediante medidas empíricas informadas por el instituto de investigación Latinobarómetro. Se han revelado al menos dos impases de las democracias latinoamericanas: primero, la reserva de compromiso con el régimen es pequeña, demostrado por el bajo apoyo de las sociedades a la democracia y a su estructura institucional; segundo, es cada vez menos efectiva la legitimidad democrática, lo que es demostrado por las elevadas tasas de insatisfacción y desconfianza tanto con el desempeño del régimen como con la actuación de la clase política tradicional.

PALABRAS CLAVE: legitimidad política, compromiso democrático, democracia representativa, América Latina.

\footnotetext{
* Este artículo se inserta en el ámbito de proyecto de investigación Evaluando la calidad de la democracia en países de América Latina (II), apoyado con beca de productividad por el Consejo Nacional de Desarrollo Científico y Tecnológico (CNPq).

** Doctora en Ciencia Política, investigadora asociada de la FAPESP y CNPQ.

*** Doctor en Ciencia Política, investigador adjunto de la UFSCar.
} 


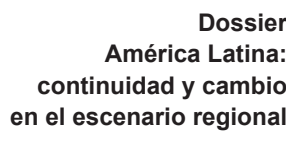

Dossier

\begin{abstract}
Given the context of alternation of political groups closer to the extreme right in Latin American countries in the last national elections, the objective of this article is to assess political attitudes of citizens and their relationship with changes in the political regime that allow us to identify the level of the "reservoir of political legitimacy" and commitment to democracy in this region. This analysis is done through empirical measures of the Latinobarómetro. The study revealed at least two impasses of Latin American democracies: first, the reservoir of commitment to the political regime is very low, demonstrated by the low support of societies for democracy and their institutional structure; second, democratic legitimacy is becoming less effective, as there are high rates of dissatisfaction and distrust with the performance of both the political regime and the performance of the traditional political class.
\end{abstract}

KEYWORDS: political legitimacy, democratic commitment, representative democracy, Latin America.

\section{Introducción}

Las últimas elecciones $(2017,2018)$ en América Latina revelaron un proceso de cambio de ciclo político en varios países. Así, si entre mediados de los años 90 y las dos primeras décadas del siglo XXI se tuvo la llegada al poder nacional de partidos de izquierda, en los últimos años partidos de derecha han vuelto al control político. En algunos de esos casos candidatos con un programa más próximo a la extrema derecha vencieron la elección presidencial, revertiendo la tendencia anterior de apoyo del electorado que era para el centro de espectro político ideológico. El más reciente fue en Brasil en 2018, cuando el pequeño Partido Social Liberal (PSL) eligió al ex capitán de reserva y exdiputado federal Jair Bolsonaro, consiguiendo capitalizar la insatisfacción e indignación de los electores con los partidos políticos tradicionales por medio de campaña electoral basada sobre las redes sociales, propagando ideas radicales de derecha. El PSL inclusive eligió la segunda mayor bancada de la Cámara Baja, 4 senadores para la Cámara Alta y 3 gobernadores de importantes estados. Hubo en general una amplia renovación parlamentar en el sistema partidario que ya había sido reorganizado durante la redemocratización, en los años 80 , resultando en una grave crisis de los partidos más relevantes.

Al mismo tiempo la región sufrió crisis en sus sistemas políticos provenientes de interrupciones de mandatos presidenciales impuestas por los parlamentos y de escándalos de corrupción envolviendo diversos agentes políticos y económicos, poniendo en descrédito una amplia parte de la clase política. Para Pérez-Liñán (2007), cuatro condiciones fueron esenciales para el desencadenamiento de un proceso de impeachment en países de América Latina de la tercera ola de democratización, al menos hasta 2004: 
crisis económica, escándalo político, indignación popular y falta de apoyo legislativo ${ }^{1}$.

Ante este contexto de crisis políticas y alternancia de grupos políticos de campos ideológicos más extremados, buscamos en este artículo evaluar actitudes políticas de los ciudadanos y su relación con los cambios en el régimen político que nos permitan identificar cuál es el nivel de la "reserva de legitimidad" de la democracia. Para alcanzar estos objetivos este trabajo fue estructurado de la siguiente manera: en la próxima sección limitamos el alcance teórico de esta discusión y definimos las dimensiones de análisis. En seguida, presentamos el contexto y los resultados de las últimas competiciones político-electorales de la región. En la sección siguiente se verifica cuál es el estado del compromiso democrático de los ciudadanos latinoamericanos y la legitimidad de la democracia y su efectividad por medio de la evaluación de múltiples actitudes políticas. En la última sección desarrollamos las conclusiones.

\section{Legitimidad política y compromiso democrático}

Para los propósitos de este trabajo el concepto de legitimidad política partirá de la definición weberiana de dominación racional/legal (1999: 139), según la cual para que un régimen democrático garantice su legitimidad es imprescindible que la mayoría de los dirigentes y de los ciudadanos acepten reglas, normas y principios inherentes a la competencia política. Pero para garantizar la estabilidad de las incertidumbres derivadas de las disputas electorales, el paso siguiente, según Lipset (1959), sería evaluar la efectividad de la legitimidad. Preocupado con los requisitos sociales de la democracia, Lipset entiende por efectividad cuánto el sistema político satisface las funciones básicas del gobierno, según las expectativas de la población dominada y de los dirigentes. La legitimidad pasa a referirse a la capacidad del sistema político de mantener la creencia de que las instituciones democráticas son las más adecuadas para la sociedad.

Sin embargo, quien consolidó el concepto de legitimidad a partir de un enfoque multidimensional fue Easton (1975). Su teoría distingue dos tipos de apoyo político: mientras que el primero, el "apoyo difuso", está relacionado con la dimensión más básica y abstracta del sistema político, el segundo, el "apoyo específico", se refiere a los aspectos más prácticos y concretos de su funcionamiento. Es importante resaltar que, en esta distinción analítica,

1 Pérez-Liñán (2007) analiza el período histórico entre 1992 y 2004, cuando seis presidentes latinoamericanos enfrentaron procesos de impeachment y cuatro fueron destituidos de sus funciones. Los casos analizados son Fernando Collor de Mello (Brasil, 1992), Carlos Andrés Pérez (Venezuela, 1993), Ernesto Samper (Colombia, 1996), Abdalá Bucaram (Ecuador, 1997), Raúl Cubas Grau (Paraguay, 1999) y Luis González Macchi (Paraguay, 2002).
Legitimidad y compromiso democrático. Impases contemporáneos en América Latina

Maria do Socorro Sousa Braga Gabriel Avila Casalecchi 
Dossier América Latina: continuidad y cambio en el escenario regional el apoyo a la democracia no está necesariamente vinculado a las evaluaciones de los ciudadanos sobre el empleo de las instituciones democráticas y sus liderazgos.

Seligson y Muller (1987), analizando la democracia de Costa Rica, concluyeron que desde que haya una "reserva de apoyo" a la democracia, actitudes como la insatisfacción e indignación políticas son absorbidas por la dinámica democrática. Al contar con una "reserva de apoyo", inclusive ante un escenario con crisis económicas y políticas, los públicos insatisfechos con el desempeño de los gobernantes pueden recurrir al voto para castigarlos y elegir otros políticos.

Sin embargo, en la realidad política de la América Latina en ese inicio del siglo XXI, países clasificados como democráticos, pero con contexto adverso de recesión, desempleo, criminalidad y escándalos de corrupción, eligieron en estas últimas elecciones gobiernos con un discurso y programa autoritarios. En esos casos, ¿hasta qué punto la opción por candidatos de la extrema derecha reflejó un compromiso democrático?

Ante problemas como éstos, otros estudios desarrollaron el concepto de compromiso democrático (Recabarren-Silva 2014), de acuerdo con el cual para medir la fuerza del apoyo a la democracia se debe saber si los ciudadanos prefieren ese régimen político $y$, adicionalmente, cuál es la disposición para rechazar regímenes autoritarios frente a escenarios críticos. Hay, por lo tanto, dos polos que se complementan: uno positivo, en el que la preferencia por la democracia es evaluada en términos abstractos, y otro polo negativo, marcado por el rechazo a las alternativas no democráticas en contextos que son desfavorables.

Para desarrollar esas y otras preguntas, y teniendo como referencia el trabajo de Easton (1965) y otros más recientes (Norris 1999, Dalton 2004, Booth y Seligson 2009), expandiremos las subdivisiones del apoyo político en diferentes dimensiones. Resaltamos así el supuesto enfatizado por Casalecchi (2018: 50-51), de acuerdo con el cual "una visión multidimensional de la legitimidad permite distinguir la orientación de los ciudadanos en relación con los diferentes objetos de la política, haciendo más claras las complejas combinaciones de actitudes de los individuos y, consecuentemente, posibilitando una evaluación más sobria de sus causas, así como de su impacto sobre el régimen político “.

A partir de ese referencial teórico, en este trabajo se utiliza el siguiente conjunto de variables: el compromiso democrático, que consiste en combinar variables de preferencias por la democracia (polo positivo) y de rechazo a regímenes autoritarios (polo negativo) en situaciones de crisis económica y política; y la legitimidad política, que será medida por las siguientes dimensiones: el apoyo a la democracia, el apoyo a las instituciones políticas, la evaluación del desempeño del régimen, la satisfacción y confianza en las instituciones político-electorales. Este análisis es realizado mediante medidas empíricas proporcionadas por el instituto de investigación Latinobarómetro. 


\section{¿Cambio o estabilidad de ciclo político?}

Desde 2014 América Latina viene profundizando una fuerte crisis multidimensional. A pesar de que existen aspectos específicos de un país a otro, se observa que esta crisis, que se está extendiendo como un movimiento, involucra varias dimensiones, entre las que se destacan la económica, política, social y moral. En este ambiente de inestabilidad, las últimas disputas políticas revelan una tendencia de un giro a la derecha en algunos de los países, siguiendo la tendencia de otras regiones del globo, pero verificamos una mayor complejidad ideológica en esta región.

En la tabla 1 es posible observar los grupos ideológicos que actualmente están dominando en los diferentes países de Latinoamérica.

Esta clasificación revela que hay países, como Bolivia, Venezuela, Uruguay, Ecuador, que eran de izquierda y continúan siendo de izquierda; países que eran de derecha y fueron a la izquierda, casos de México y Costa Rica; países como Argentina y Brasil que eran de izquierda y fueron a la derecha y extrema derecha, respectivamente. No obstante, la mayor parte de los países eran de derecha y continúan de derecha. $\mathrm{Y}$ en esos sectores crece el apoyo popular a los candidatos con propuestas más próximas a la extrema derecha.

¿Pero cuál es el perfil de la derecha? La derecha, tradicionalmente, se dividía en tres grupos: los conservadores, que se oponían de manera moderada al cambio, con la esperanza de que éste pudiera ser controlado por ellos; los reaccionarios, que deseaban restaurar el pasado; y los fascistas o contrarrevolucionarios, que compartían con los reaccionarios su odio al presente y a las ideas comunistas, pero diferían de ellos por sus métodos violentos, su oportunismo y su radicalismo. En términos partidistas, esos grupos de derecha o extrema derecha se organizaban en partidos o movimientos cuyos discursos políticos habían sido clasificados de: fascistas, neofascistas, extremistas de derecha, radicales de derecha, populistas, totalitarios, nueva derecha radical (Betz 1994, 1998; Norris 2005; Givens 2005).

Algunos de los partidos que llegaron al poder en esas últimas elecciones en la región son considerados como de extrema derecha o "nueva derecha radical". Estos partidos presentan las siguientes características: primero, no son partidos de masa, a diferencia de los partidos fascistas de la primera mitad del siglo veinte, las bases populares y sectores medios en las que se apoyan votan en ellos pero no se organizan en extensas redes de militantes; en segundo lugar, los partidos de la derecha radical niegan cualquier vínculo con la violencia, inclusive si ocurren episodios aislados, mientras que los partidos fascistas alentaban la violencia y defendían públicamente la violencia de masas; el tercero, sus militantes no constituyen grupos armados y uniformados como los SS y las camisas negras o marrón, aunque atraen la simpatía de grupos milicianos, neonazis y skinheads, conforme la presencia de esos sectores en cada país (Sala 2006, Buford 1992, Konopnicki 1996, Schröder 1992, Brauner-Orthen 2001). Son partidos que, aunque adoptan temas antidemocráticos durante la
Legitimidad y compromiso democrático. Impases contemporáneos en América Latina

Maria do Socorro Sousa Braga Gabriel Avila Casalecchi 


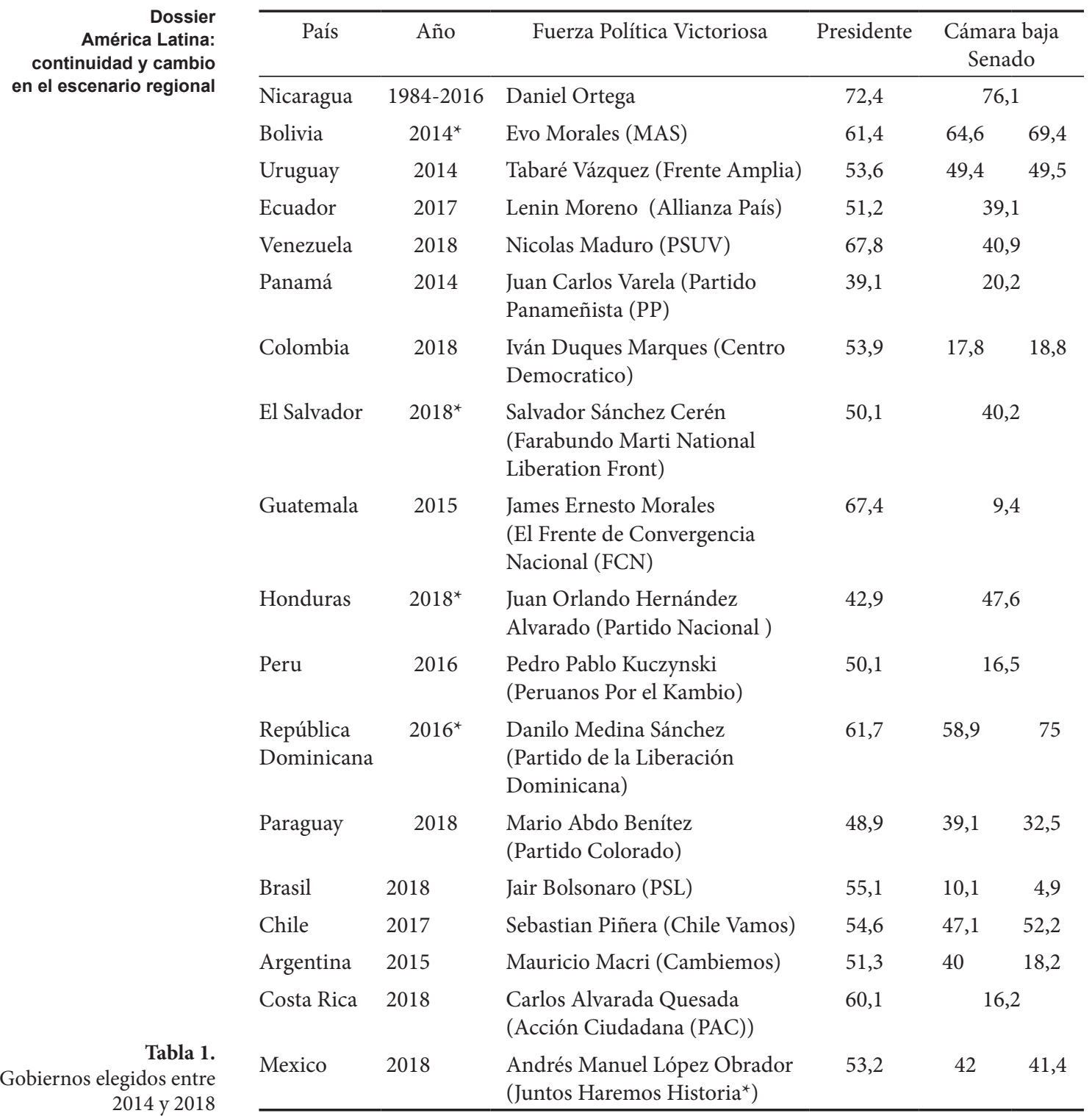

Fuente: www.electionguide.org. ${ }^{\text {. }}$

${ }^{a}$ Clasificación: la parte desde arriba hasta la República Dominicana: gobiernos de continuidad ideológica (izquierda y continúan de izquierda, derecha y continúan de derecha); la parte siguiente: gobiernos que cambiaron de ideología (izquierda y cambaron para derecha, derecha y cambiaron para izquierda). 
campaña política y a lo largo de la administración gubernamental, particularmente en las cuestiones sociales, de valores y morales, llegaron a los gobiernos nacionales a través de las elecciones y mantuvieron las instituciones democráticas funcionando. Otro importante impacto que causaron fue en el cambio de los sistemas partidarios regionales, resultando en una fuerte alteración de posición del poder entre los partidos hasta entonces dominantes.

Entre los trabajos clásicos, como el de Bobbio (1995), definimos, en términos ideológicos, como partidos de izquierda aquellos que apuntan, como una de sus prioridades, la búsqueda de una mayor igualdad tanto en el aspecto socioeconómico, con la reducción de la disparidad entre las clases sociales, como en el status de diferentes grupos, defendiendo, por ejemplo, más equidad entre géneros y etnias. En términos de acción política, los gobiernos de izquierda privilegian al Estado como instrumento para reformular la sociedad y la economía, adoptando una postura crítica con respecto a la posibilidad de que el mercado logra solucionar, solo, todas las demandas sociales. En el marco de este referencial teórico, Madrid, Hunter y Weyland (2010) apuntan, a partir de las especificidades de los países gobernados por las izquierdas en América Latina, la existencia de tipos distintos de izquierdas. En ese sentido, los gobiernos en la tabla son clasificados por los autores como izquierdas "contestatarias" (en el caso del gobierno de Hugo Chávez en Venezuela y del gobierno de Evo Morales en Bolivia) y como izquierdas "moderadas" (en el caso del gobierno de Lula en Brasil y el gobierno de Bachelet en Chile).

En cuanto a la definición del régimen democrático, seguimos los requisitos establecidos por Diamond y Morlino (2005), que, a su vez, derivan del clásico trabajo de Dahl (1971). Según los autores, una democracia requiere: a) sufragio universal; b) elecciones libres, frecuentes, justas y competitivas; c) más de un partido político serio; y d) fuentes de información alternativas. En el marco de los cuatro requisitos anteriores, los autores aclaran también que las democracias no deben estar sometidas a las restricciones por parte de grupos e instituciones -internas o externas- sino que presten cuentas directa o indirectamente de sus acciones a la población y que, para haber elecciones libres y justas, es necesario que los regímenes cuenten con libertades civiles y políticas que permitan a los ciudadanos organizarse en torno a sus intereses y posiciones políticas.

Para entender estos procesos, el trabajo de Mair (2006), al llamar la atención sobre dos tendencias importantes que tuvieron impacto reciente en los partidos y en los sistemas partidistas europeos, puede ayudar a entender también la dirección del cambio observado anteriormente en los sistemas partidarios de esta región. La primera tendencia es la "victoria de la democracia" que llevó a la desaparición de los partidos antisistema tradicionales. "En la política contemporánea y probablemente por primera vez en la historia democrática, casi todos los partidos se han vuelto aceptables ", afirma (Mair 2006: 69).

Este diagnóstico es válido incluso para los partidos de la derecha radical que, aunque se diferencien de los demás partidos por sus propuestas o por
Legitimidad y compromiso democrático. Impases contemporáneos en América Latina

Maria do Socorro Sousa Braga Gabriel Avila Casalecchi 
Dossier América Latina: continuidad y cambio en el escenario regional su "estilo peculiar de hacer política", concuerdan plenamente con ellos cuando se trata del compromiso con el mantenimiento de los procedimientos democráticos. Por más improbables e innegables que puedan parecer sus propuestas para muchos electores, los partidos tradicionales logran en algunos casos construir acuerdos y plataformas comunes con los partidos radicales e incorporarlos al gobierno, en una demostración cabal de que las diferencias de orientación política, por mayores que sean, son siempre negociables. La segunda tendencia observada por Mair es la declinación de los partidos como organizaciones que agregan afiliados. En consecuencia, los partidos actuales se parecen cada vez más unos a otros, sobre todo en el modo en que se comportan en la escena política y en la manera de comunicarse y relacionarse con la sociedad. En la evaluación de Mair, la combinación de estas dos tendencias sugiere que los sistemas partidarios caminan cada vez más hacia sistemas bipolares, que mejor reflejan las disputas electorales en torno a personajes y no a programas partidistas. Así, los extremos del espectro político son progresivamente rehabilitados, pues ayudan a los electores a diferenciar los dos campos en disputa (Mair 2007).

Otros aspectos relevantes del contexto latinoamericano que están relacionados con el escenario político-partidario revelado en la tabla 1, marcado por la intercalación ideológica en la administración de algunos de esos países, se apuntan, en especial, a la situación de la clase media latinoamericana que ha sufrido en la última década un bajo crecimiento económico y un aumento en la sensación de inseguridad y de violencia. Además de esto, el fin del ciclo de redemocratización de muchos países latinoamericanos viene siendo marcado por la decepción con una clase política involucrada en profundos casos de corrupción y con cuestionamientos al modelo de financiamiento de campaña electoral. Como resultado, el comportamiento de ese segmento tuvo un peso determinante sobre el rechazo a la clase política de los partidos tradicionales en las últimas elecciones. Este cansancio hacia los políticos tradicionales favoreció el surgimiento de políticos que se presentaron como independientes, novatos y a veces técnicos o incluso apolíticos, redundando en el ascenso de populistas y "salvacionistas". Como consecuencia de esto, en esos países, viene creciendo el rechazo a los partidos políticos más antiguos y aumentando la adhesión a líderes de partidos de extrema derecha.

Entre los factores transversales de este contexto de problemas destacamos la fuerte crisis económica. Según datos del Fondo Monetario Internacional, el P.I.B viene cayendo a cada año, del 6\% en 2010 al 0\% en 2015 y llegando a ser negativo en 2016. En el año siguiente presentó ligera recuperación (aproximadamente el $1 \%)$.

La recuperación en curso sigue siendo pequeña frente al tamaño de la caída registrada. Como sabemos, el bajo crecimiento tiene un impacto directo en la intención de voto de la población, pues puede minar la importancia de las ganancias sociales alcanzadas a lo largo de la última década en términos de empleo, desigualdad y reducción de la pobreza. Esto explica, en buena medi- 


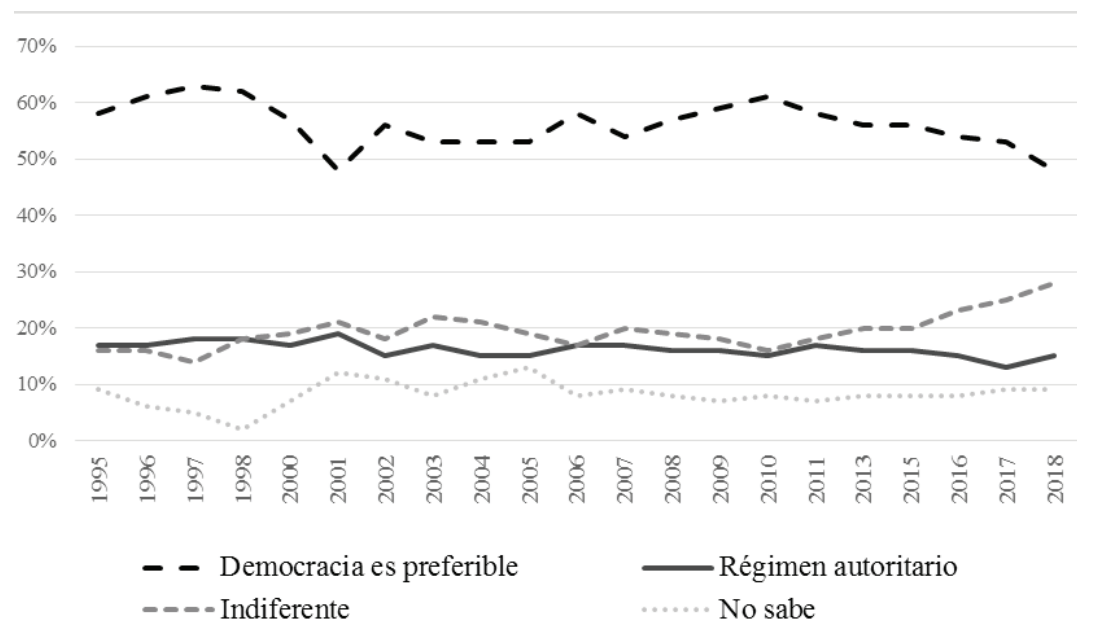

Fuente: Latinobarómetro (1995-2018)

da, el menor apoyo recibido por gobiernos progresistas, como, por ejemplo, en Brasil y Argentina, en las contiendas electorales analizadas.

\section{Evaluando la "reserva de apoyo" a la democracia entre los públicos latinoamericanos}

A partir de las pistas observadas en la sección anterior, en esta parte será verificado cómo está el compromiso democrático de los ciudadanos. Para ello, se combinan dos tipos de apoyos. El primero es el polo positivo del compromiso, que puede ser medido por el apoyo de los ciudadanos a la democracia a partir de la pregunta: "Con cuál de las siguientes frases usted está más de acuerdó? 1) La democracia es preferible a cualquier otra forma de gobierno, 2) En algunas circunstancias un gobierno autoritario pode ser preferible a uno democrático; o 3) A personas como yo, les da lo mismo un régimen democrático o uno no democrático".

De acuerdo con la secuencia histórica de los últimos 20 años el apoyo a la democracia se mantuvo relativamente estable a lo largo del período, con poco menos del $60 \%$ de la población latinoamericana apoyando el régimen. Al mismo tiempo, se observa que hubo muy pocos picos de fuerte reducción de ese apoyo en años con aumento de la retracción de la economía. El caso más serio se produjo durante la crisis asiática, cuando sólo el $48 \%$ de la población se mantuvo apoyando la democracia. Es decir, hay más variables -no solo las económicas- relacionadas con las actitudes antidemocráticas observadas.

Es importante notar que el porcentaje de ciudadanos que prefiere un régimen autoritario se mantuvo también prácticamente establecido a lo largo de
Legitimidad y compromiso

democrático. Impases

contemporáneos

en América Latina

Maria do Socorro Sousa Braga

Gabriel Avila Casalecchi

\section{Gráfico 1.}

Apoyo a la democracia. América Latina (1995-2018) 


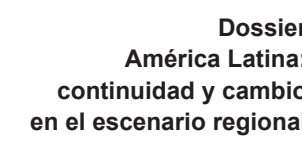

Gráfico 2 .

Apoyo a golpes militares y golpes ejecutivos.

América Latina

(2004-2016/17)

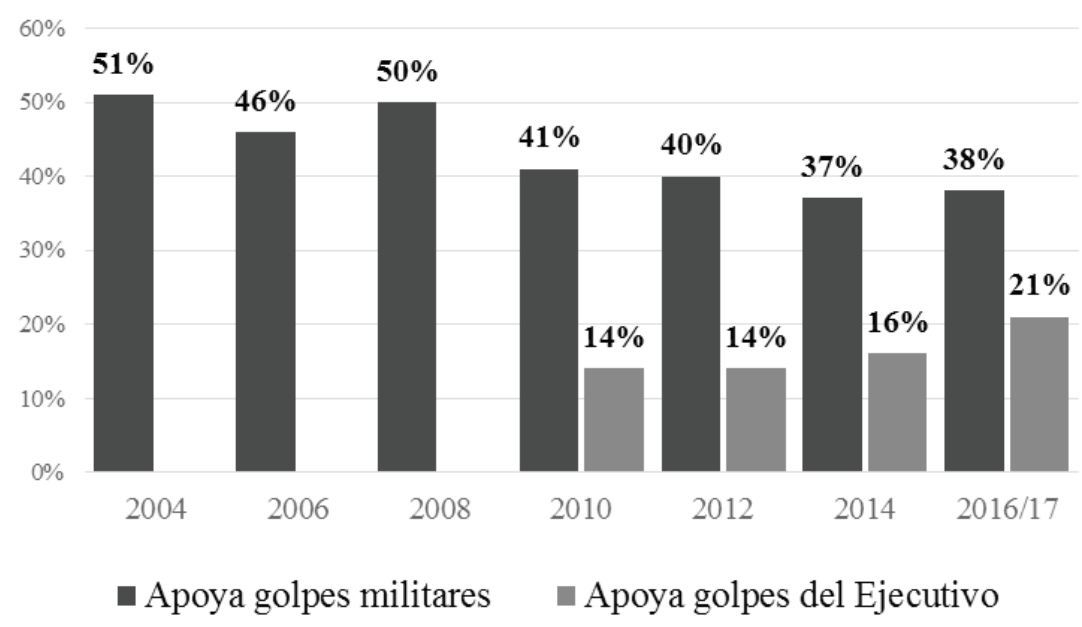

Fuente: AmericasBarometer (2004-2016/17)

los 20 años, indicando una ligera tendencia a la baja en los últimos años. Sin embargo, esta reducción en ese público no redundó en el aumento del apoyo a la democracia, sino en el crecimiento de la tasa de latinoamericanos que son indiferentes al tipo de régimen; el aumento fue del 11\% de 1995 a 2018. Juntando los dos segmentos, aquellos que apoyan regímenes autoritarios y los indiferentes al tipo de régimen, ya son casi el $43 \%$ de los ciudadanos que desprecian la democracia.

En lo que se refiere al polo negativo del compromiso democrático, el gráfico 2 presenta el porcentaje de ciudadanos que "aceptarían un golpe militar en caso de mucha corrupción", según lo preguntado por el LAPOP en las encuestas realizadas desde 2004 hasta 2018. Se puede ver que los niveles de apoyo a golpes militares permanecen relativamente estables desde 2010, entre el 38\% y el $41 \%$. A pesar de esta estabilidad, no deja de ser preocupante que más de $1 / 3$ de la población latinoamericana apoye un golpe militar, aunque en un caso hipotético de mucha corrupción.

Otra pregunta que también nos ayuda a identificar el polo negativo del compromiso democrático es el apoyo al cierre del Congreso por parte del Poder Ejecutivo en tiempos de dificultades. El porcentaje de los que apoyan esta medida es menor que aquellos que apoyan un golpe militar en caso de mucha corrupción. Sin embargo, la diferencia de esta última actitud ha aumentado en los últimos años. De 2014 a 2017, el porcentaje de ciudadanos que apoyaría el cierre del Congreso por el Ejecutivo saltó del 16\% al 21\%, alcanzando su récord histórico.

Estos resultados permiten avanzar en el entendimiento de lo que fue llamado aquí "reserva democrática" en el contexto de América Latina. Se destaca que la preferencia por la democracia ha disminuido en la región. Las personas 
están cada vez más desilusionadas o indiferentes con la democracia como la mejor forma de gobierno entre las alternativas posibles. Esta incredulidad con la democracia no significa necesariamente un apoyo por alternativas militares. Sin embargo, no es excesivo destacar que, aunque el apoyo explícito a un golpe militar sea rechazado por la mayoría de los ciudadanos, ha crecido el número de los que apoyan la intervención del Ejecutivo sobre el Legislativo, por medio de medidas como el cierre del Congreso Nacional.

Se puede concluir que la "reserva de apoyo a la democracia" en América Latina tiene sus límites cuando se trata del compromiso de sus ciudadanos. Varios factores pueden estar relacionados con esa actitud. Pero hay fuertes indicios de que esa indiferencia sea el resultado del desencanto de los ciudadanos con la política, como veremos en la sección siguiente. Este desencanto despierta preocupación porque abre camino para posibles retornos de gobiernos autoritarios.

\section{Legitimidad de régimen democrático en América Latina}

Existen dos cuestionamientos contrapuestos por estudiosos del comportamiento político (Norris 1999, Dalton 2004) que involucran a la mayor parte de las democracias actuales: ¿la región vive crisis de representación política

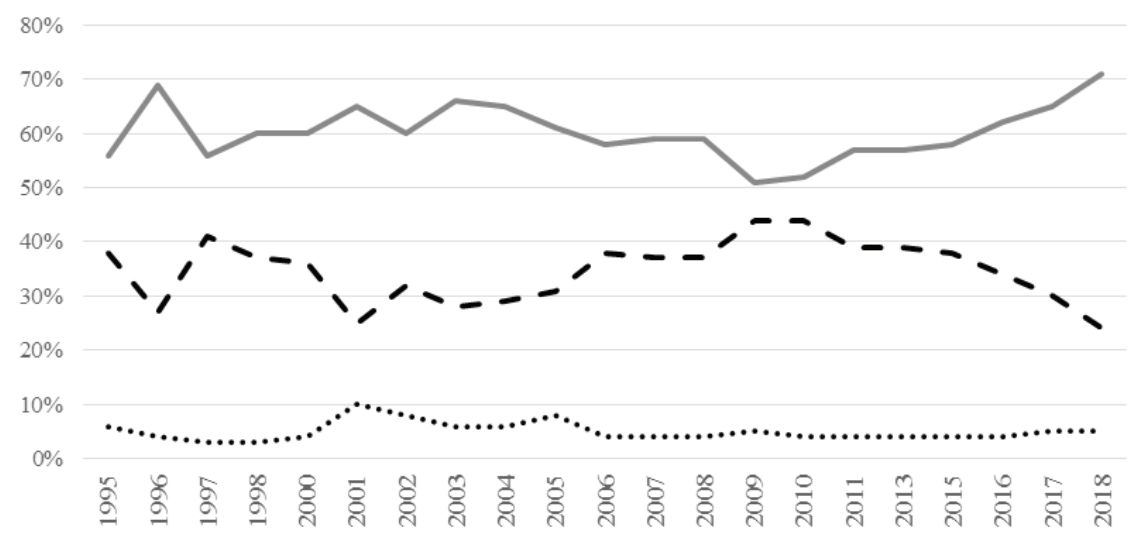

- - Satisfecho con la democracia

- Insatisfecho No sabe
Legitimidad y compromiso democrático. Impases contemporáneos en América Latina

Maria do Socorro Sousa Braga Gabriel Avila Casalecchi

Gráfico 3.

Satisfacción con la democracia. América Latina (1995-2018)

Fuente: Latinobarómetro (1995-2018)

o de legitimidad de régimen democrático? El argumento principal de estos autores es que cuando existe una desconfianza en las instituciones representativas, pero no sobre la democracia por sí misma, estamos ante una crisis de representación. Sin embargo, cuando esa desconfianza va acompañada de baja 
Dossier América Latina: continuidad y cambio en el escenario regional adhesión a la democracia y apoyo a medidas autoritarias, estamos hablando de una crisis de legitimidad del régimen. En ese sentido, es necesario llamar la atención a los problemas de estructuración de los vínculos de representación de la sociedad con el régimen.

Ya se ha visto que el apoyo al régimen en la región ha caído en las últimas décadas, afectando uno de los pilares de sustentación de la estructura de la legitimidad democrática, pero ¿y las demás dimensiones? ¿Cuál es el posicionamiento de los ciudadanos en lo que se refiere a la efectividad del funcionamiento del régimen? La efectividad de la legitimidad se evalúa aquí a partir de dos dimensiones: el grado de satisfacción con su funcionamiento y el grado de confianza con sus instituciones representativas.

De acuerdo con el gráfico 3 es cada vez mayor la cantidad de ciudadanos satisfechos con el modus operandi de las democracias latinoamericanas, alcanzando $71 \%$ a fines del período analizado. Se puede decir que las evidencias indican que la satisfacción con el desempeño del sistema político disminuye drásticamente en la medida en que hay una caída acentuada del P.I.B. En otras palabras, en contexto adverso, como discutido anteriormente, el sistema político no fue capaz de funcionar de acuerdo con las expectativas de la mayor parte do electorado.

En la Tabla 2, es posible observar, que en diez países menos de un tercio de la población está satisfecha con la democracia. Sólo en tres países: Uruguay (57\%), Nicaragua (52\%) y Ecuador (51\%), hay una mayoría que está satisfecha con su funcionamiento. Se observa que, en los países donde la mayoría está satisfecha, hay continuidad de gobiernos de izquierda, como mostrado en la tabla 1. Por otro lado, en países que eligieron gobiernos de derecha o de extrema derecha, la insatisfacción con el desempeño de la democracia alcanzó niveles muy altos, quedando Brasil (13\%) y Paraguay (23\%) debajo del promedio de la región (30\%). Inclusive Argentina (38\%) y Chile (36\%) quedaron un poco arriba del promedio, demostrando que el reservatorio democrático de esos países está cada vez más frágil.

Pero ¿cómo está la confianza del latinoamericano en las instituciones democráticas? Para evaluar esta segunda dimensión se seleccionaron cinco instituciones básicas responsables directamente por el proceso político electoral y gubernativo: el voto secreto, los partidos políticos, los tribunales electorales, el congreso y el poder ejecutivo. La suposición es que cuanto mayor es la confianza en esas instituciones, mayor es la consistencia en la estructuración de esos vínculos sociales con el marco institucional.

Según el Latinobarómetro de 2017, el dispositivo del voto secreto, fundamental para ampliar la autonomía del elector e incentivar su participación en las disputas políticas, tiene un promedio de más del 60\% de confianza en la región. Este dato revela que la cuestión del voto secreto está bastante consolidada, es un valor democrático.

Sin embargo, la confianza en los partidos políticos (Gráfico 4), además de presentar los índices más bajos entre todas las instituciones analizadas, alcan- 


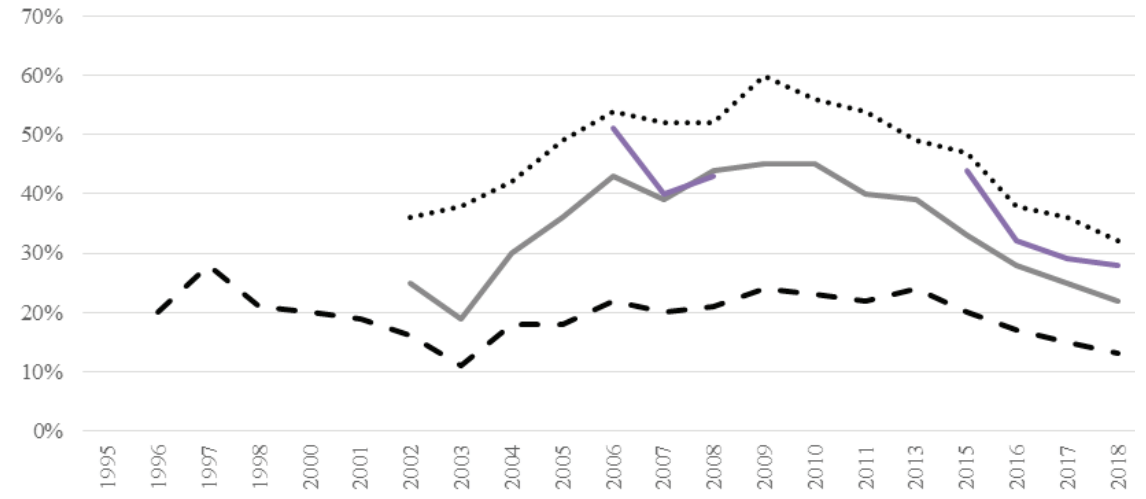

- Confianza en los Partidos Políticos

Confianza en el gobierno

....... Aprobación de lo gobierno

Confianza en los Tribunales Electorales
Legitimidad y compromiso

democrático. Impases

contemporáneos

en América Latina

Maria do Socorro Sousa Braga

Gabriel Avila Casalecchi

\section{Gráfico 4.}

Confianza en los partidos, en el gobierno, aprobación del gobierno y confianza en los tribunales electorales. América Latina (1995-2018)

Fuente: Latinobarómetro (1995-2018)

za el más débil grado al final del período estudiado. Sólo cinco países están por encima del 15\%, el promedio de la región (Uruguay, Nicaragua, Ecuador, Argentina y Honduras).

Se sabe que la primera condición para que los partidos puedan constituirse en canales de decisión de voto tiene que ver con la capacidad de conectarse con los electores, creando apoyos más o menos estables. Como esta capacidad se adquiere con la experiencia continua de elecciones, en las que los mismos partidos son los principales competidores se debería esperar un crecimiento, aunque pequeño, de la confianza.

En cuanto a la confianza en los tribunales electorales (Grafico 4) se verifica una fuerte caída del promedio al final del período analizado, con nueve países por debajo del promedio regional (Tabla 2). Pero no sólo las instituciones responsables del proceso electoral, partidos y tribunales electorales, son constantemente mal evaluadas, también lo son los Poderes Ejecutivos y Legislativos, y consecuentemente la clase política.

En cuanto a los datos del grafico 4, se observa que además de la disminución de la confianza en el congreso a lo largo del período, 10 países muestran una confianza por debajo del promedio latinoamericano. El descrédito en la clase política es general, pero ha aumentado en los años de denuncias de corrupción, como veremos a continuación.

En cuanto a la confianza en el gobierno, hubo un ligero aumento del promedio en algunos años, declinando al final del período. En 2017, nueve países quedaban por debajo del $25 \%$, el promedio de la región. 


\begin{tabular}{|c|c|c|c|c|c|c|}
\hline \multirow[t]{16}{*}{$\begin{array}{r}\text { Dossier } \\
\text { América Latina: } \\
\text { continuidad y cambio } \\
\text { en el escenario regional }\end{array}$} & & $\begin{array}{l}\text { Satisfacción } \\
\text { con la } \\
\text { democracia }\end{array}$ & $\begin{array}{l}\text { Confianza en } \\
\text { los partidos }\end{array}$ & $\begin{array}{l}\text { Confianza en } \\
\text { los tribunales }\end{array}$ & $\begin{array}{l}\text { Aprobación } \\
\text { del gobierno }\end{array}$ & $\begin{array}{c}\text { Se gobierna } \\
\text { para grupos } \\
\text { poderosos }\end{array}$ \\
\hline & Argentina & $38 \%$ & $18 \%$ & $27 \%$ & $36 \%$ & $73 \%$ \\
\hline & Bolivia & $35 \%$ & $15 \%$ & $30 \%$ & $57 \%$ & $56 \%$ \\
\hline & Brasil & $13 \%$ & $7 \%$ & $25 \%$ & $6 \%$ & $97 \%$ \\
\hline & Chile & $36 \%$ & $14 \%$ & $31 \%$ & $33 \%$ & $81 \%$ \\
\hline & Colombia & $17 \%$ & $10 \%$ & $22 \%$ & $30 \%$ & $85 \%$ \\
\hline & Costa Rica & $45 \%$ & $12 \%$ & $46 \%$ & $50 \%$ & $79 \%$ \\
\hline & Ecuador & $51 \%$ & $20 \%$ & $27 \%$ & $66 \%$ & $58 \%$ \\
\hline & El Salvador & $15 \%$ & $8 \%$ & $18 \%$ & $17 \%$ & $85 \%$ \\
\hline & Guatemala & $26 \%$ & $11 \%$ & $25 \%$ & $38 \%$ & $64 \%$ \\
\hline & Honduras & $29 \%$ & $16 \%$ & $20 \%$ & $47 \%$ & $64 \%$ \\
\hline & México & $18 \%$ & $9 \%$ & $33 \%$ & $20 \%$ & $90 \%$ \\
\hline & Nicaragua & $52 \%$ & $22 \%$ & $30 \%$ & $67 \%$ & $43 \%$ \\
\hline & Panamá & $26 \%$ & $10 \%$ & $29 \%$ & $22 \%$ & $81 \%$ \\
\hline & Paraguay & $23 \%$ & $12 \%$ & $17 \%$ & $21 \%$ & $88 \%$ \\
\hline & Perú & $16 \%$ & $11 \%$ & $38 \%$ & $30 \%$ & $80 \%$ \\
\hline $\begin{array}{r}\text { Tabla } 2 . \\
\text { ctitudes y percepciones }\end{array}$ & $\begin{array}{l}\text { República } \\
\text { Dominicana }\end{array}$ & $32 \%$ & $15 \%$ & $23 \%$ & $52 \%$ & $87 \%$ \\
\hline bre la democracia y las & Uruguay & $57 \%$ & $25 \%$ & $51 \%$ & $41 \%$ & $62 \%$ \\
\hline América Latina (2017) & Venezuela & $22 \%$ & & $32 \%$ & $32 \%$ & $69 \%$ \\
\hline
\end{tabular}

Fuente: Latinobarómetro 2017

Problemas económicos (bajos salarios, ..

Delicuencia / seguridad publica

La economía/problemas.

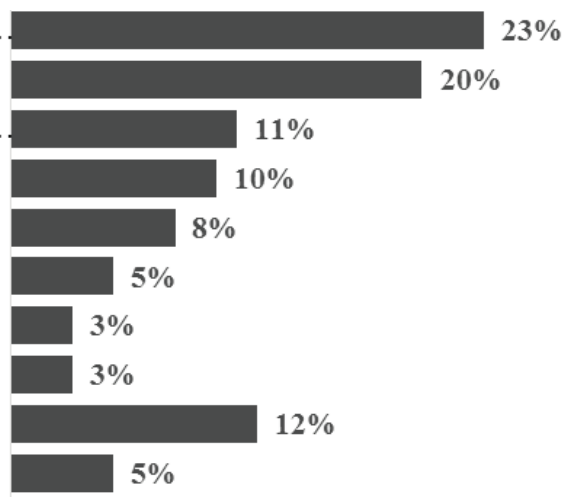

Corrupción

Situacíon / problemas de la política

Problemas de la educacíon

Problemas de la salud

Violencia/pandillas

Otros

No sabe

$\mathbf{5 \%}$

país. América Latina 2017

Fuente: Latinobarómetro (2017) 
Esta fuerte desconfianza de la actuación de la clase política en la arena gubernativa conduce al segundo estancamiento contemporáneo que afecta la legitimidad de la democracia. Se trata de la crisis de gobernabilidad en sistemas multipartidarios y presidencialistas y la formación de mayorías necesarias.

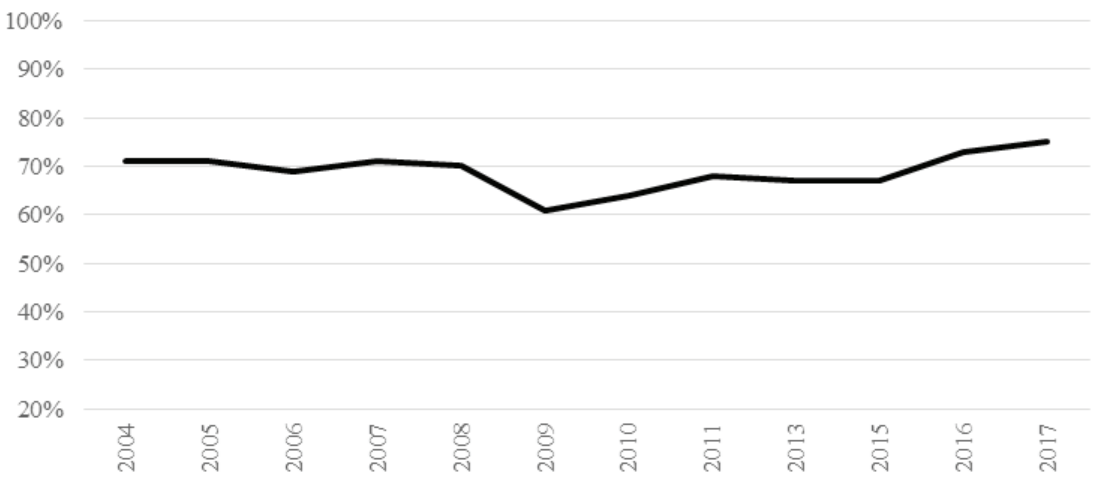

Fuente: Latinobarómetro (2017).

La tasa promedio de aprobación de los gobiernos en América Latina tuvo un aumento considerable en el período de 2005 a 2010, luego se observa la caída de esa tasa al nivel inicial de la serie histórica estudiada. Período en el que también se inicia el giro a la derecha en la región. Sin embargo, vale la pena notar que en 2017 países con administraciones progresistas (Nicaragua, $67 \%$, Ecuador, $66 \%$ y Bolivia, $57 \%$ ) son los que fueron mejor aprobados en la región.

¿Y qué puede estar asociado al rechazo de buena parte de los gobernantes en el último periodo analizado? La pregunta sobre cuál era el mayor problema del país, ilustrada en el gráfico 5, nos da algunas pistas. En primer lugar, están los problemas relacionados con la crisis económica, en segundo lugar, el aumento de la inseguridad y, en tercer lugar, la corrupción.

Pero en los datos siguientes, aparecen indicadores mucho más contundentes asociados a la reprobación del gobernante. Primero, de acuerdo con Latinobarómetro, en 2017, más de la mitad de los ciudadanos en la región consideraba muy deficiente la lucha del gobierno contra la corrupción. Los países con las peores tasas fueron Brasil (80\%), Chile (69\%), Venezuela (68\%) y Colombia $(66 \%)$. A excepción de los venezolanos los demás ciudadanos castigaron a sus presidentes eligiendo candidatos de otros grupos políticos. En segundo lugar, como se observa en el grafico 6, son aún más elevadas las tasas medias relacionadas con la percepción de los ciudadanos de que la actuación de los gobernantes está orientada a satisfacer sus intereses personales y de ciertos grupos poderosos en perjuicio de la mayoría de la población, llegando
Legitimidad y compromiso democrático. Impases contemporáneos en América Latina

Maria do Socorro Sousa Braga Gabriel Avila Casalecchi

\section{Gráfico 6.}

Respuesta a la pregunta: ¿Diría Ud. que (el país) está gobernado por unos cuantos grupos poderosos en su propio beneficio, o que está gobernando para el bien de todo el pueblo? 
Dossier América Latina: continuidad y cambio en el escenario regional al 75\% en 2017, siendo aún más altas en países como Brasil (97\%), México (90\%) y Paraguay (88\%), entre otros.

Finalmente, los indicadores analizados revelan que el posicionamiento de los ciudadanos en cuanto a la efectividad del funcionamiento del sistema político, ya sea en términos de las instituciones representativas o en lo que se refiere a las funciones básicas del gobierno, denota frágil "reserva de legitimidad política”. Como bien apuntó Lipset (1965), cuanto mayor es la insatisfacción y la desconfianza de los ciudadanos con el desempeño del sistema político mayor la dificultad de los dirigentes políticos mantener la creencia de que las instituciones políticas son las más adecuadas para aquella sociedad. En consecuencia, el subsistema político tendrá más probabilidades de sufrir un colapso en su funcionamiento.

\section{Conclusiones}

La evaluación del compromiso democrático involucrando a los ciudadanos y las elites políticas y la efectividad de la legitimidad del sistema político reveló al menos dos impases de las democracias latinoamericanas. En primer lugar, la reserva de compromiso con el régimen es muy baja, demostrada por el bajo apoyo de las sociedades latinoamericanas a la democracia y a su estructura institucional. En segundo lugar, es cada vez menos efectiva la legitimidad democrática, demostrada por las elevadas tasas de insatisfacción y desconfianza con el desempeño tanto del régimen, al no dar cuenta de funciones básicas de gobierno, como con la actuación de la clase política tradicional, envuelta en denuncias de corrupción y responsabilizada por la mala distribución de los bienes públicos.

La combinación de una baja legitimidad y compromiso democrático con la percepción negativa de la efectividad de las instituciones y del gobierno sirve como una alerta para la democracia en América Latina. Al componer la "tercera ola democrática" (Huntington 1990), la mayoría de los países de la región vive el ciclo democrático más largo de su historia, con gobiernos democráticos escogidos por medio de elecciones periódicas, libres y competitivas. El problema, sin embargo, es que, a diferencia de las soluciones autoritarias del pasado, en las que predominaban los golpes militares, el avance autoritario se da en el interior de las instituciones democráticas.

Siguiendo los hallazgos de Levitsky y Ziblatt, en el libro Cómo las democracias mueren, esa incredulidad y frustración de los ciudadanos latinoamericanos también están abriendo camino a gobernantes con un perfil más autoritario y que capitalizan un sentimiento "antisistémico". Este perfil más autoritario está proviniendo tanto de la derecha como de la izquierda. Lo que ocurre es que en algunos países latinoamericanos hubo una fuerte frustración con ciertos gobiernos de izquierda, particularmente después del conocimiento de la implicación de sus principales líderes políticos en graves episodios de corrupción (Argentina y Brasil). En fin, por los datos analizados se nota que 
la región está ampliando sus crisis de representación político-partidaria (alta insatisfacción con los partidos políticos, con el Parlamento y con el desempeño de la clase política tradicional) y entrando en una crisis de legitimidad del régimen democrático como mostraron los indicadores con respecto a la caída en la adhesión a la democracia, el aumento de la insatisfacción con su funcionamiento y la desaprobación de los gobernantes.

\section{Referencias bibliográficas}

Betz H.G., Immerfall S. (eds.) (1994), Radical Right-Wing Populism in Western Europe, St. Martin's Press, New York.

Betz H.G., Immerfall S. (eds.) (1998), The New Politics of the Right: Neo-Populist Parties and Movements in Established Democracies, St. Martin's Press, New York.

Bobbio N. (1995), Direita e esquerda: razões e significados de uma distinção política, Editora UNESP, São Paulo.

Booth J., Selison M. (2009), The Legitimacy Puzzle: Democracy and Political Support in Eight Latin American Nations, Cambridge University Press, Cambridge.

Brauner-Orthen, A. (2001), Die NeueRechte in Deutschland: Antidemokratische und rassistischeTendenzen, Leske + Budrich, Opladen.

Buford B. (1992), Entre os vândalos - A multidão e a sedução da violência, Companhia das Letras, São Paulo.

Casalecchi G. A. (2018), Legado democrático e apoio à democracia na América Latina. Evidências e mecanismos explicativos, Ed. UFPR, Curitiba.

Dahl R. (1971), Polyarchy: Participation and Opposition, Yale University Press, New Haven.

Dalton R. J. (2004), Democratic Challenges, Democratic Choices: The Erosion of Political Support in Advanced Industrial Democracies, Oxford University Press, Oxford.

Deutsch S. M. (1999), Las Derechas - The Extreme Right in Argentina, Brazil, and Chile 1890-1939, Stanford University Press, Stanford.

Diamond L., Morlino L. (eds.) (2005), Assessing the Quality of Democracy, Johns Hopkins Univ. Press, Baltimore.

Easton D. (1965), A System Analysis of Political Life, Wiley, New York.

Easton D. (1975), A Re-assessment of the Concept of Political Support, "British Journal of Political Science", vol. 5, no 4, October, Cambridge, pp. 435-457.

Givens T. E. (2005), Voting Radical Right in Western Europe, Cambridge University Press, Cambridge.

Konopnicki G. (1996), Les filières noires, Denoël, Paris.

Latin American Public Opinion Project (Lapop) (2017), Barómetro de las Américas 2017.

Latinobarómetro (2011), Informe 2011, disponible en: www.latinobarometro.org.

Lipset S. M. (1959), Some Social Requisites of Democracy: Economic Development and Political Legitimacy, "American Political Science Review", vol. 53, no 1, March, pp. 69-105.
Legitimidad y compromiso democrático. Impases contemporáneos en América Latina

Maria do Socorro Sousa Braga Gabriel Avila Casalecchi 
Dossier América Latina: continuidad y cambio en el escenario regional
Madrid R., Weyland K., Hunter W. (2010), Leftists Governments in Latin América: Successes and Shortcomings, Cambridge University Press, Cambridge.

Mair P. (2006), Party System Change, en: Handbook of Party Politics, R. S. Katz, W. Crotty (eds.), Sage, London, pp. 63-73.

Mair P. (2007), Left-Right Orientations, en: The Oxford Handbook of Political Behavior, R. J. Dalton, H.D. Klingemann (eds.), Oxford University Press, Oxford, pp. 206-222.

Norris P. (2005), Radical Right: Voters and Parties in the Electoral Market, Cambridge University Press, Cambridge.

Norris P. (1999), Critical Citizens: Global Support for Democratic Government, Oxford University Press, Oxford.

Pérez-Liñán A. (2007), Presidential Impeachment and the New Political Instability in Latin America, Cambridge University Press, New York.

Recabarren-Silva L. (2014), Lógicas de rechazo a la democracia en América Latina: más allá de una aproximación dicotómica al apoyo a la democracia, Tesis, Departamento de Ciencias Políticas y Sociales, Universidad Pompeu Fabra, Barcelona.

Salas A. (2006), Diário de um skinhead - Um infiltrado no movimento Neonazista, Planeta, São Paulo.

Schröder B. (1992), Rechte Kerle: Skinheads, Faschos, Hooligans, Rowohlt, Hamburg.

Seligson M. A., Muller E. N. (1987), Democratic Stability and Economic Crisis: Costa Rica, 1978-1983, "International Studies Quarterly", vol. 31, no 3 (Sept.), pp. 301-326.

Weber M. (1999), Os três tipos puros de dominação legítima, en: Sociologia, 7, G. Cohn, W. Max (org.), Ed. Ática, São Paulo. 